\title{
Enhancement and Segmentation Techniques for Palm-Leaf Manuscript Images
}

\author{
Akara Thammastitkul
}

\begin{abstract}
Palm leaf manuscripts were a very important evident of our historic. The contents in palm-leaf manuscript were about medicine, Buddhist doctrine, astrology and religion. Mostly palmleaf manuscripts were found in the damaged sources. This paper has proposed the enhancement techniques for palm-leaf manuscript images. The proposed method consists of image acquisition, color model selection, noise reduction, image enhancement and segmentation. The resulted images shown more visible character which could be used in the recognition step, in the future.
\end{abstract}

Keywords - Palm-Leaf Manuscript, Enhancement, Image.

\section{INTRODUCTION}

Palm-leaf manuscripts is a valuable ancient document. It is the oldest form of writing. They are mostly written in term of literacy, historical, religion, astrology, traditional and Buddhist medicine. It is a very valuable and important national cultural heritage [1]. Due to an organic in nature of palm-leaf manuscripts, they are subject to physical damage and decay. As the time passes by, the most manuscripts have been destroyed owing to the tropical climate of the region, insect and improper collection method [2-6]. The letter on palm leaf are very rare and may not visible to read. In literature review, Surinta, O. \& Chamcong, R. [7-8] used Otsu's algorithm, line segmentation and histogram method to segment the text from manuscitps. S. Phattarachairawee \& M. Ketcham [9] transformed image to grayscale image, a contrast stretching and histogram equalization are used.

From the pass, the decay palm-leaf manuscript are copied from generations to generations by a professional man handwritten which it is a skilled activity. Nowadays, a professional manuscript writer is rare. Then, to preserve the palm-leaf manuscript, images of manuscripts are captures and stored in electronic files. But with the low quality of manuscript leads to the low quality images. A reading or replication are difficult and timeless. This paper proposed method to enhance the images into a viewable images in order to preserve this valuable resources and knowledge.

\section{II.PROPOSED METHOD}

\section{A. Image Acquisition}

The palm-leaf manuscript images are taken from Tong-Tua temple in Chanthaburi province, Thailand. The 50 images are used. They are RGB images with $640 \times 490$ pixels size. The palm-leaf manuscript were written in the difference period of time and condition. The images are collected in nonuniform illumination. Palm-leaf manuscript images are shown in Fig. 1.

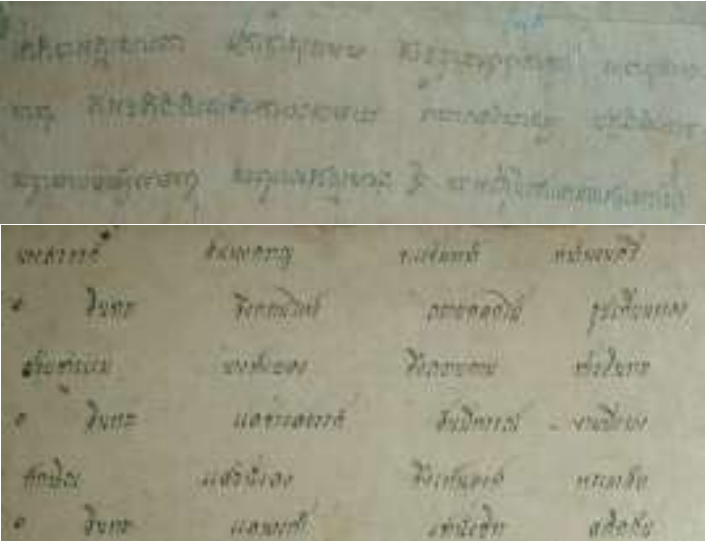

Fig. 1: Example of palm-leaf manuscript image

\section{B. Color Model Selection}

In this paper, we experiment on RGB and HSI color model. The original image are in RGB color model. Each color is expressed as a combination of its three primary colors, i.e., red $(\mathrm{R})$, green (G), and blue (B). The HIS color model represents a color in term of hue $(\mathrm{H})$, saturation (S), and intensity (I) or value (V). Hue represents a dominant wavelength of a color. Saturation refers to the purity of a color. Intensity represents the brightness of a color. Each color in RGB and HSI color mode are shown in Fig.2 and Fig. 3. From the result shown that image in intensity color is the clearest image. 


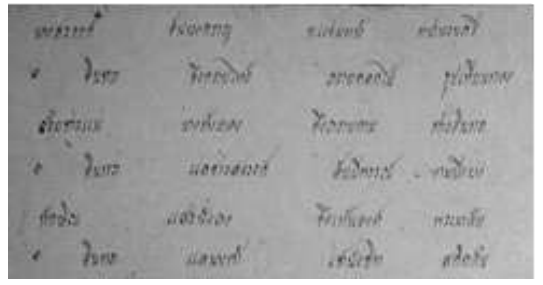

(a)

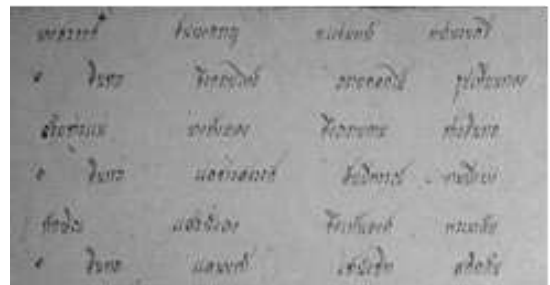

(b)

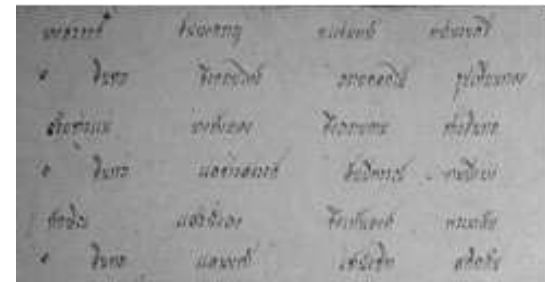

(c)

Fig. 2: RGB color model (a) red (b) green (c) blue

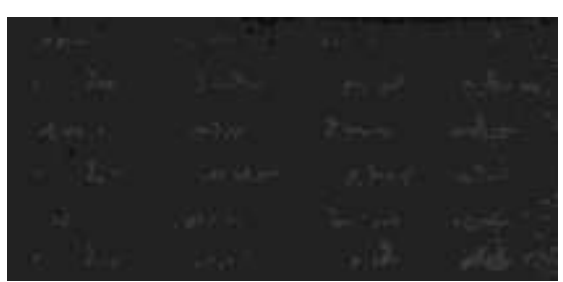

(a)

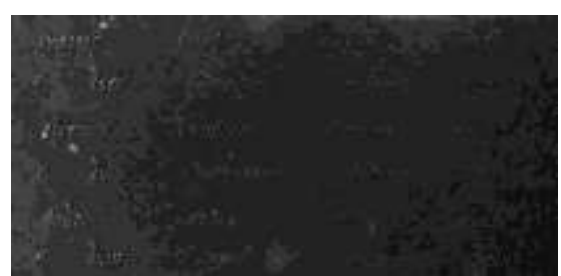

(b)

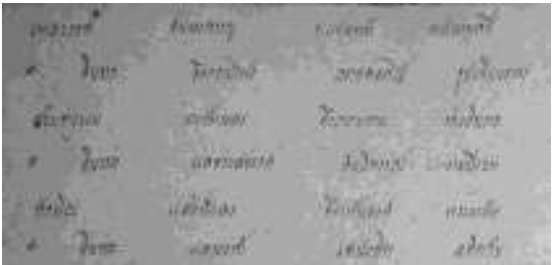

(c)

Fig. 3: HSI color model (a) hue (b) saturation (c) intensity.

\section{C.Noise Reduction}

In order to remove noise, median filter and weighted averaging filter are experimented. The median filter replace the value of a pixel by the median of the gray levels in the

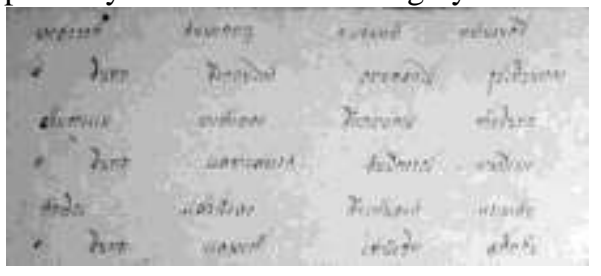

(a) neighbourhood while weighted averaging filter convolved a mask with an image. Median filter is selected as it is robust method and it preserves the sharp edges. The result shown in Fig. (4).

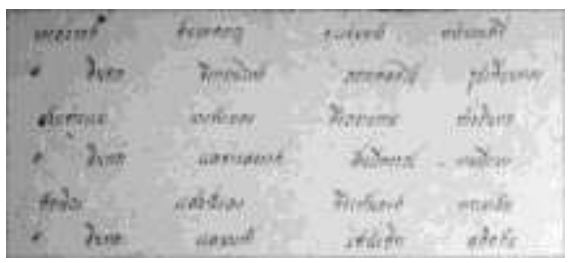

(b)

Fig. 4: Noise reduction (a) median filtering (b) average filtering

\section{D.Image Enhancement and Segmentation}

In this step, three enhancement methods are applied to enhance the contrast of the image [10]. Gray level transformations, histogram equalization and Contrast Limited Adaptive Histogram Equalization (CLAHE) [11-12] are image enhancement techniques in spatial domain. Image enhancement used the function $\mathrm{T}$ to map the intensity value of input image to the intensity value of output image.

$$
\mathrm{s}=\mathrm{T}(\mathrm{r})
$$

where $r$ : input gray levels, $s=$ output gray levels

Histogram equalization determines a gray level transformation function that produces an output image with a uniform histogram. Histogram equalization improves image contrast, but not work for background variation. Contrast Limited Adaptive Histogram Equalization (CLAHE) is used to correct the limitation of normal histogram equalization. Normal histogram equalization is a global enhancement while CLAHE is a local enhancement. And it different from AHE by its contrast limiting. The results are shown in Fig. (5).

Adaptive thresholding [13] are applied to segment text characters from the background. The dark character are segmented. Normal thresholding is not work well on nonuniform illumination image as it's a global thresholding. Adaptive thresholding computes a local threshold based on the local mean intensity in the neighborhood of each pixel. The results are shown in Fig. (6). 

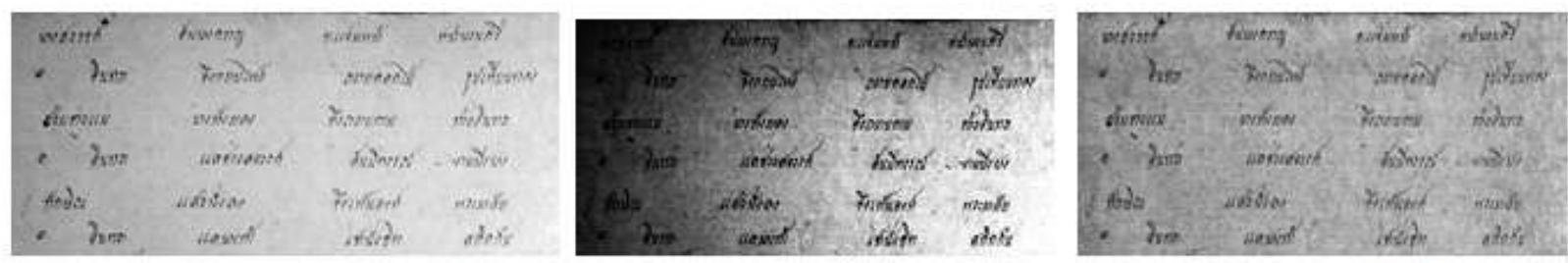

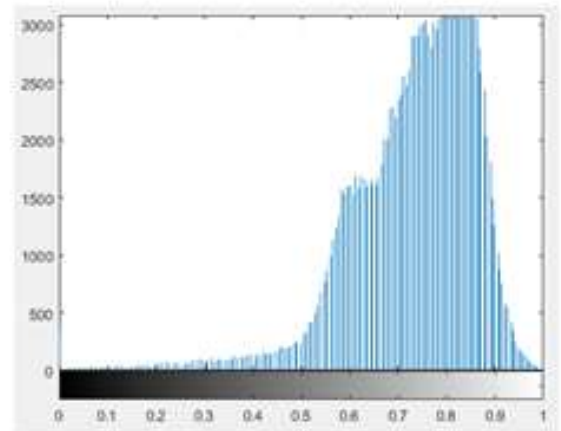

(a)

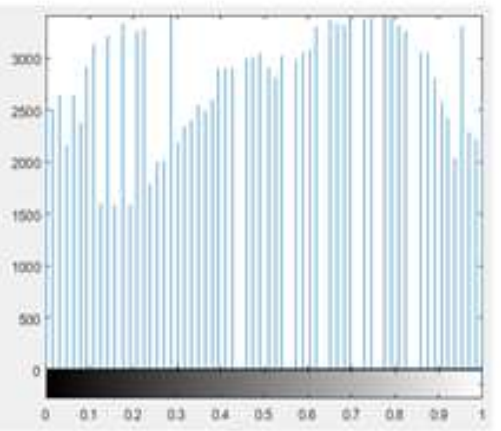

(b)

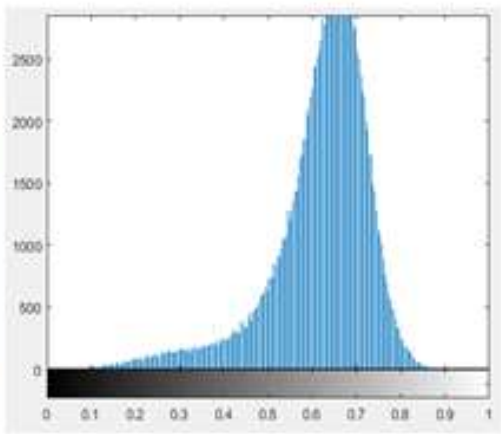

(c)

Fig. 5: Image enhancement's results and its histogram (a) gray-level transformation (b) histogram equalization (c) CLAHE

\begin{tabular}{|c|c|c|c|}
\hline sosmen & dsaveng & furkons & miturent \\
\hline - lun & Fomethe" & aneneove & gotowen \\
\hline chisinat & SWMER & $x_{\text {Xavem }}$ & mingus \\
\hline - 3nm & uatizens of & Woms & $=v x^{2}$ \\
\hline finds & wastign: & 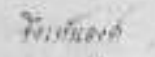 & masis \\
\hline - $\quad$ Synt & Hownt & Fisiven & anto 6 \\
\hline
\end{tabular}

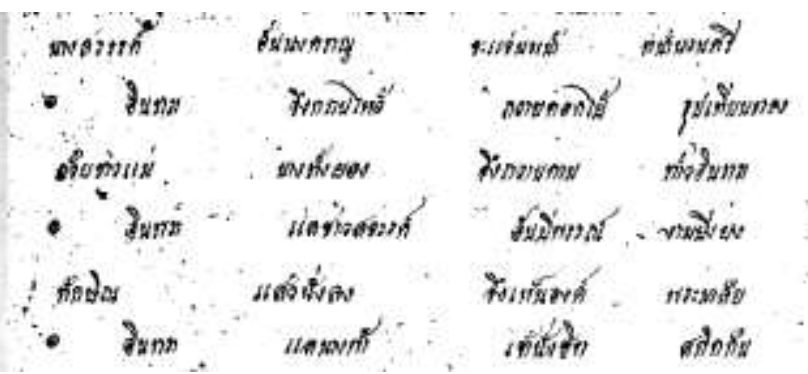

(a)

\begin{tabular}{|c|c|c|c|}
\hline & browntig & sinfons & rolown? \\
\hline & Tropus & Anenaode & plirosme \\
\hline & invisiaer & Tinvems: & mishms \\
\hline & Whesionsen & XWh & $\left.v_{2}\right)$ \\
\hline & vasition. & Tेursand & MT:QnAS \\
\hline b) & Hasunt & iningth & $\cos ^{2} R_{2}$ \\
\hline
\end{tabular}

(b)

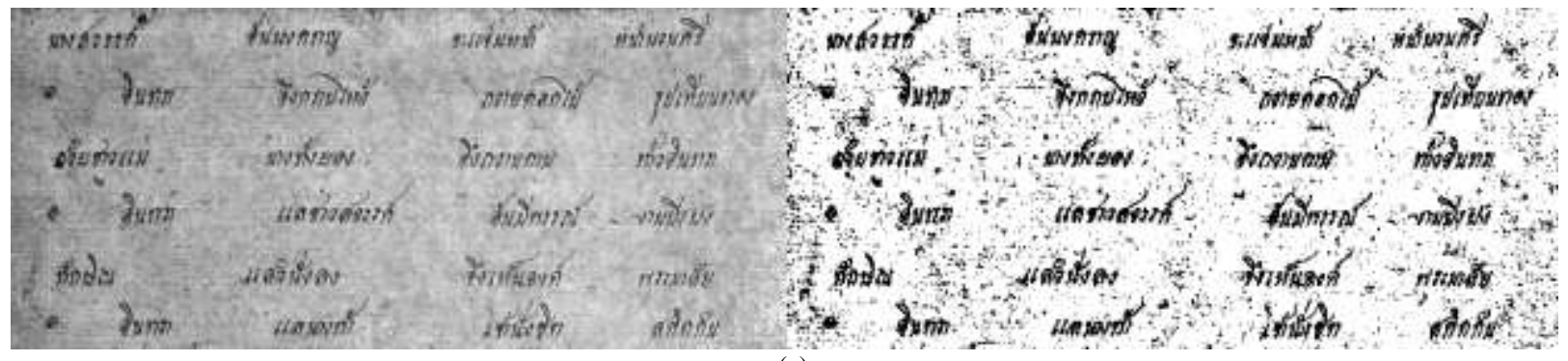

(c)

Fig. 6: Adaptive threshold results (a) adaptive thresholding on gray-level transformation (b) adaptive thresholding on histogram equalization (c) adaptive thresholding on CLAHE.

\section{RESULT AND DISCUSSION}

The 50 palm-leaf manuscript images are tested. The original RGB color images are transform to HSI color image. The suitable color mode 'intensity' is used. A median filtering is used in noise reduction. A gray level transformation is used in image enhancement. And adaptive thresholding is used in segmentation step. The histogram of enhanced image's result 
using histogram equalization is uniform and look good but it is not work well on segmentation step cause of in the segmentation step we need the input image as very dark on text and very white on background. The results shown that our proposed method is suitable for text character from palm-leaf manuscripts. We found that one of the cause of unsegmentation text is a very decay images. They are still have some unwanted dark pixels and not continuous text line. Morphology method could help to improve the image quality. Dilation and Erosion method will be experimented in the next phase.

\section{CONCLUSION}

Due to a quality of palm-leaf manuscripts, text character segmentations is difficult. Efficiency preprocessing method are required. Color mode selection, noise elimination and image enhancement are experimented in this paper. The good preprocessed image leads to good segmentation. Our proposed method can enhance the images in which suitable for the segmentation. The text character segmented could be used for further recognition step.

\section{ACKNOWLEDGEMENTS}

This research is funded by Faculty of Humanities and Social Sciences, Burapha University.

\section{REFERENCES}

[1] Unesco. (2014). Memory of Asia Project to preserve palm-leaf manuscripts of Asia. Available: http://www.instituteofasianstudies.com/palmleaf.html

[2] Chowdhury, G.G., Chowdhury, S, "Digital library research: major issues and trends." Journal of Documentation. 55 (4), 1999, pp. 409-448. https://doi.org/10.1108/EUM0000000007154

[3] Sahoo J., \& Mohanty, B, "Giving Life to Palm Leaf Manuscripts: Technological Aspects." The Orissa Historical Research Journal. Vol. xlvi, No. 2, 2003, pp. 108-112.

[4] Tacnet LL-SAZB, "Text Line Segmentation of Historical Documents: a Survey." International Journal on Document Analysis and Recognition, Analysis of Historical Documents. 2006.

[5] Gaur, Ramesh C, "Preservation and Access to Manuscript Heritage in India." International Journal of Information Research. 1(1), 2011, pp. $1-15$.

[6] Ghosh Rituparna, "Palm Leaf Manuscrips Conservation - A Study." Global Research Methodology Journal, 4(3), 2012.

[7] Surinta, O. \& Chamchong, R., "Image Segmentation of Historical Handwriting from Palm Leaf Manuscript." in IFIP International Federation for Information Processing, 288, Intelligent Information Processing IV; Zhongzhi Shi, E. Mercier-Laurent, D. Leake; (Boston: Springer), 2008, pp. 182-189.

[8] Chamchong R and Surinta O, "Text Line Segmentation from Palm Leaf Manuscripts." In Proc. the 3rd National Conference on Computing and Information Technology (NCCIT2007), 2007.

[9] S. Phattarachairawee and M. Ketcham, "An algorithm image Enhancement for Segmentation Palm-Leaf Manuscript." In Proc. of International Conference on Digital Arts, Media and Technology (ICDAMT), 2017, pp. 378-382. https://doi.org/10.1109/ICDAMT.2017.7904996

[10] Gonzalez, R.C. \& R.E. Woods, Digital Image Processing, Reading, Massachusetts, U.K.: Addison-Wesley. 1992, pp.716.

[11] G. Yadav, S. Maheshwari and A. Agarwal, "Contrast limited adaptive histogram equalization based enhancement for real time video system," in Proc. 2014 International Conference on Advances in Computing, Communications and Informatics (ICACCI), 2014, pp. 2392-2397. https://doi.org/10.1109/ICACCI.2014.6968381
[12] A Raji, A Thaibaoui, E Petit, P Bunel, G Mimoun, "A gray-level transformation-based method for image enhancement, Pattern Recognition Letters, vol. 19, no. 13, pp. 1207-1212, 1998. https://doi.org/10.1016/S0167-8655(98)00109-3

[13] Bradley, D., G. Roth, "Adapting Thresholding Using the Integral Image," Journal of Graphics Tools, vol. 12, no. 2, pp. 13-21, 2007. https://doi.org/10.1080/2151237X.2007.10129236 